\title{
Sıcaklık, Hormon ve Vejetasyon Süresinin Isatis tinctoria L. ve Isatis buschiana Schischkin tohumlarının Çimlenmesi Üzerine Etkisi ve Tohum Olgunluğunun Yağ Kalitesi ile İlişkisi
}

\author{
*Nazan Çömlekcioğlu \\ Şengül Karaman \\ Mehtap Kutlu \\ Kahramanmaraş Sütçü İmam Üniversitesi, Fen-Edebiyat Fakültesi, Biyoloji BI., Kahramanmaraş \\ *Sorumlu yazar e-posta (Corresponding author; e-mail): noktem@ksu.edu.tr \\ Geliş Tarihi (Received): 11.11.2015 Kabul Tarihi (Accepted): 02.12.2015
}

Öz

Bu çalışmada farklı vejetasyon sürelerine sahip I. tinctoria ve I. buschiana tohumlarının çimlenmeleri üzerine farklı sıcaklıkların $\left(5,10,15,20\right.$ ve $\left.25^{\circ} \mathrm{C}\right)$ etkisi incelenmiştir. Ayrıca vejetasyon süresinin tohumların yağ oranı ve içeriği üzerine etkileri GC-MS yardımıyla analiz edilmiştir. I. tinctoria tohumlarının çimlenmesi üzerine farklı vejetasyon sürelerinin etkisi önemsizken, I. bushiana'da önemli olmuştur. Her iki türün tohumlarının çimlenmesi $5^{\circ} \mathrm{C}$ 'de daha geç başlamış, bu nedenle çimlenme oranının bu sıcaklıkta daha düşük olduğu belirlenmiştir. Tohumların $5^{\circ} \mathrm{C}$ 'de çimlenmesi üzerine $\mathrm{GA}_{3}$, Putresin ve ALA hormonlarının farklı konsantrasyonlarının etkileri incelenmiştir. I. buschiana ve I. tinctoria tohumlarının $5^{\circ} \mathrm{C}$ 'de $\mathrm{GA}_{3}$ 'ün sırasıyla 50 ppm ve 75 ppm konsantrasyonlarında çimlenmelerinin arttığı gözlenmiştir. Her iki türün tohumlarının yağ oranı ve içeriğinin farklı vejetasyon sürelerinde benzer olduğu tespit edilmiştir.

Anahtar Kelimeler: Isatis, yağ, çimlenme, $\mathrm{GA}_{3}, \mathrm{ALA}$, Putresin

\section{Effects of Temperature, Hormone and Vegetation Period on the Germination of Isatis tinctoria L. and Isatis buschiana Schischkin Seeds and Relationship between Seed Maturity and Oil Quality}

\begin{abstract}
In this study, effects of different temperature values $\left(5,10,15,20\right.$ and $\left.25^{\circ} \mathrm{C}\right)$ on the germination of $I$. tinctoria and $I$. buschiana seeds, which have different vegetation periods, were investigated. Effects of vegetation periods on the ratio and components of seed oil were also analyzed by using GC-MS. While different vegetation periods were not effected the germination of $I$. tinctoria seeds, germination of $I$. buschiana seeds were differed according to vegetation periods. Late germination was observed in the seeds of both species at $5{ }^{\circ} \mathrm{C}$, therefore germination ratio was found to be low in this temperature value. Effects of different concentrations of $\mathrm{GA}_{3}$, Putresin and ALA on the germination ratio at $5^{\circ} \mathrm{C}$ was investigated. Germination of $I$. buschiana and $I$. tinctoria seeds were increased by $\mathrm{GA}_{3}$ with concentrations of $50 \mathrm{ppm}$ and $75 \mathrm{ppm}$, respectively, at $5^{\circ} \mathrm{C}$. The ratio and components of seed oil were found to be similar in different vegetation periods.
\end{abstract}

Keywords: Isatis, oil, germination, $\mathrm{GA}_{3}, \mathrm{ALA}$, Putrescine

\section{Giriş}

$\mathrm{D}$ ünyada yaklaşık 79 türü bulunan Isatis cinsine ait bitkilerden (Moazzeni ve ark. 2007) en çok araştırılan tür olan I. tinctoria'nın yapraklarından mavi indigo boyası elde edilmekte (Gilbert ve Cooke 2001), aynı zamanda bitkinin fungisidal, bakteriyosidal, nematosidal ve allelopatik özelliklere sahip glukozinolatları ve onların parçalanma ürünlerinin kanser önleyici nitelikleri yoğun ilgi çekmektedir (Galletti ve ark. 2006; Lin ve ark 2010; Al-Gendy ve ark. 2010). Az çalışılmış olan I. buschiana'nın yeşil aksamında indigo oranı çok düşük bulunmuş olsa da (Çömlekcioğlu ve ark. 2015; Karaman ve ark. 2015), vitamin E ve karotenin varlığı tespit edilmiştir (Azimova ve ark. 2011). Isatis cinsine ait tohumların içerdiği yağda plastik endüstrisi açısından değerli olan erusik asit bulunmaktadır (Bağcı ve Özçelik 2009). Son zamanlarda çevreye zarar vermeyen ve yenilenebilir bitki esaslı yağlayıcı ve çözücü maddeler ile bunların türevlerinin kullanımı yaygınlaşmakta olup, Avrupa Birliği'ndeki bazı ülkeler biyolojik olarak ayrışabilen, yenilenebilir ve çevreci ham maddelerin satışını ve üretimini garanti altına 

tinctoria L. and Isatis buschiana Schischkin Seeds and Relationship between Seed Maturity and Oil Quality"

almaktadır (Mungan 2005). Avrupa Birliği ayrıca sentetik olarak üretilen indigoya alternatif bir kaynak sağlamak için çivitotunun Avrupa tarımına tekrar girmesine yönelik çalışmalara fon sağlamaktadır (Çömlekcioğlu 2011).

Çivitotu bitkisinin çimlenmesi ile ilgili sınırlı bilgi vardır (Karagüzel ve Taş̧̧ığlu, 2005), üstelik doğal populasyonların kültür koşullarına tepkileri bilinmemektedir. Ancak bir türün kültüre alınabilmesi çalışmalarının ilk aşamasını söz konusu türün çoğaltılmasıyla ilgili özelliklerin belirlenmesi oluşturmaktadır (Karagüzel ve Taşcıoğlu 2005). l̇yi bir çimlenme ve toprak çıkışı bitkisel verimliliğin en önemli aşamalarından birini oluşturmaktadır (Atalay ve ark. 2011). Düzensiz ve geç çimlenme ile birlikte oluşan yabancı ot, hastalık ve zararlılar, bitki gelişimini yavaşlatarak hem verimde hem de ürünün kalitesinde olumsuz etki yapmaktadır (Erdoğan 2008). Özellikle ilkbahar ekimlerindeki düşük toprak sıcaklıkları çimlenme ve çıkışı olumsuz etkilemektedir. Bu şartlarda çıkış yapan fideler yavaş büyümekte, patojenlere karşı daha fazla hassasiyet göstermektedirler. Bu yüzden istenilen fide gelişimi ve verim potansiyeline ulaşılamamaktadır Olumsuz çevre faktörlerine veya doğrudan tohum kalite ve yapısına bağlı olarak çimlenme ve çıkış esnasında yaşanabilecek sorunları en aza indirmek, kısa sürede üniform fide çıkışı ve kuvvetli bir fide gelişimi sağlamak ve stres şartlarına dayanıklıı̆ı artırmak amacıyla ekim öncesinde tohuma yapılan çeşitli uygulamalar genel anlamda "Ekim öncesi tohum uygulamaları (Priming)" olarak adlandırımaktadır (Elkoca 2007; Kaya 2008). Tohumlara çeşitli uygulamaların yapıldığı priming yönteminin temel amacı, bazı biyokimyasal olayların tetiklenmesi ve ekimden sonra çıkışın hızlandırılmasıdır. En yaygın priming teknikleri arasında, kontrollü su alımının sadece su ile sağlandığı hydropriming, osmotik çözeltilerin

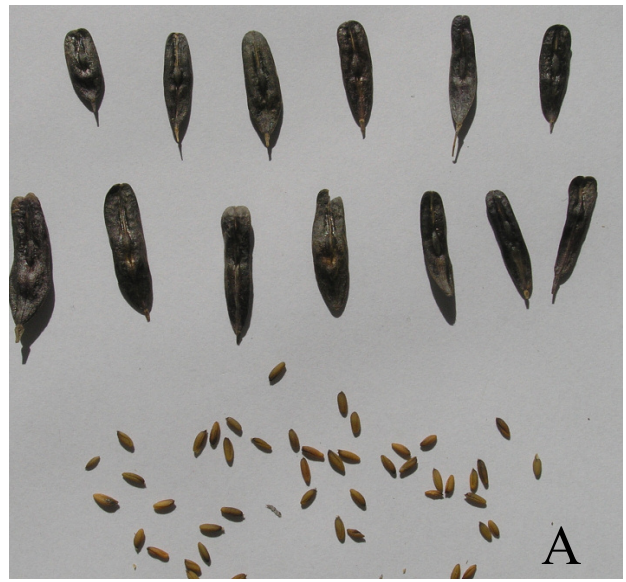

Şekil 1. I. tinctoria (a) ve I. buschiana'ya (b) ait meyve ve tohumların görüntüsü

Figure 1. I. tinctoria (a) ve I. buschiana'ya (b) ait meyve ve tohumların görüntüsü
(PEG, $\mathrm{KNO}_{3}, \mathrm{KH}_{2} \mathrm{PO}_{4}$ ) kullanıldığı osmopriming ve vermikülit gibi katı ortamların kullanıldığı matripriming gelmektedir (Kaya ve ark. 2010). Çimlenme, çıkış ve fide tutumunda faydası olan priming teknikleri (Murungu ve ark. 2004), olumsuz çevre şartlarının bitkiye vereceği zararı en aza indirmek amacıyla birçok bitki türünde uygulanmaktadır (Korkmaz ve ark. 2004). Bu yararlarından başka priming uygulamalarının stres koşulları altında büyümeyi de artırdığı çeşitli araştıııcılar tarafından ifade edilmiştir (lqbal ve Ashraf 2005). Optimum koşullarda gerçekleştirilen çimlendirme testinin tarla çıkışı ile istatistiki anlamda önemli pozitif bir ilişki verdiği bilinmektedir (Hegarty 1971).

Bu çalışmayla vejetasyon süresinin tohum çimlenmesi ve yağ içeriği gibi tohum kalite özelliklerine etkisinin olup olmadığı araştırı ımıştır. Ayrıca değişik konsantrasyonlarda uygulanan $\mathrm{ALA}, \mathrm{GA}_{3}$ ve putresinin düşük sıcaklıkta Isatis tohumlarının çimlenme performansları üzerine etkisi araştırılmıştır. Böylece düşük sıcaklıkta gerçekleştirilen ekimlerde çimlenmeyi arttırıcı etkiye sahip, uygun hormon ve optimum konsantrasyonun bulunması amaçlanmıştır.

\section{Materyal ve Yöntem}

\section{Bitki Örnekleri}

Araştırmada materyal olarak Kahramanmaraş Sütçü İmam Üniversitesi (KSÜ) Fen-Edebiyat Fakültesi Biyoloji Bölümü'nden temin edilen $I$. buchiana ve I.tinctoria'ya ait farklı vejetasyon sürelerine sahip (Ekim, Kasım, Şubat ve Mart aylarında ekilmiş fakat aynı zamanda hasat edilmiş bitkilere ait) tohumlar kullanılmıştır (Şekil 1). Tohumlar meyve kabuklarından çıkarılmış olup, benzer boyut ve görünümdeki tohumların seçilmesine özen gösterilmiştir. Çürük ve buruşuk görünümlü tohumların denemede kullanılmasından kaçınıImıştır.

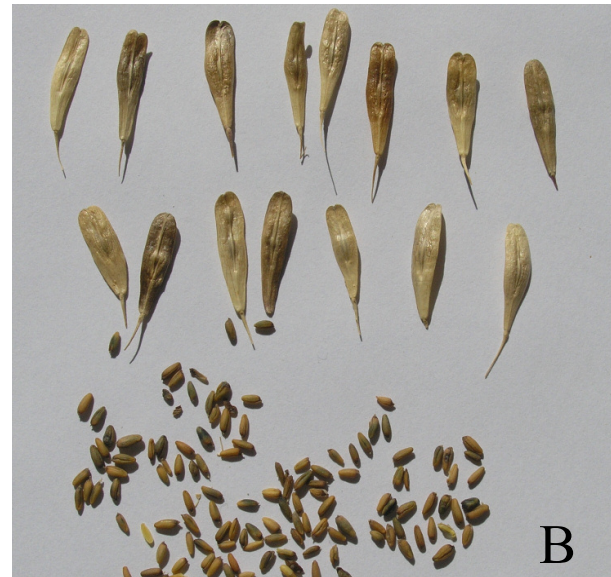


Çömlekcioğlu ve ark. "Sıcaklık, Hormon ve Vejetasyon Süresinin Isatis tinctoria L. ve Isatis buschiana Schischkin tohumlarının Çimlenmesi Üzerine Etkisi ve Tohum Olgunluğunun Yağ Kalitesi ile İlişkisi

\section{Sıcaklığın Çimlenmeye Etkisi}

Çalışma Karagüzel ve Taşçıŏlu (2005)'nun yöntemi modifiye edilerek yapılmıştır. Çimlenme testi, 3 tekerrürlü ve her tekerrürde 30 tohum olacak şekilde petri kaplarında gerçekleştirilmiştir. Sterilizasyonu \% $1.5^{\prime}$ lik sodyum hipoklorit ile yapılan tohumların (Dhanda ve ark. 2004) çimlendirilmesi sıcaklık kontrollü çimlendirme tablasında gerçekleştirilmiştir. Tohumların çimlendirilmesinde farklı sıcaklıklar $\left(5^{\circ} \mathrm{C}, 10^{\circ} \mathrm{C}, 15^{\circ} \mathrm{C}, 20^{\circ} \mathrm{C}, 25^{\circ} \mathrm{C}\right)$ denenmiştir. Kökçüğün görülmesi $(1 \mathrm{~mm})$ çimlenme için yeterli sayılmış ve her gün çimlenen tohum sayısı sayılmıştır. Sayım işlemi 30 gün boyunca devam etmiş ve çimlenme oranları \% olarak belirlenmiştir (Anonim 1996).

Hormonların düşük sıcaklıkta çimlenme performansları üzerine etkisi

Çalışma Korkmaz (2008)'in yöntemi modifiye edilerek yapılmıştır. Denemede $\mathrm{GA}_{3}$, ALA ve Putresin hormonlarının farklı konsantrasyonları $(0,25,50$ ve $75 \mathrm{ppm})$ denenmiştir. Bunun için steril tohumlar farklı konsantrasyonlardaki hormonlar ile oda sıcaklığında 24 saat muamele edilmiştir. Daha sonra tohumlar saf suda yıkandıktan sonrapetrilere alınmış ve üzerine $3 \mathrm{ml}$ saf su eklenmiştir. Parafilmle kaplanan petriler $5{ }^{\circ} \mathrm{C}$ 'deki çimlendirme tablasına bırakılarak, ışıksız ortamda çimlenme testlerine tabi tutulmuştur. Çalışmada elde edilen verilere $F$ testi ile varyans analizi uygulanmış, ortalamalar arasındaki farklılıkların karşılaştııılmasında Duncan Çoklu Karşılaştırma Testi kullanılmıştır (Akıncı ve Çalışkan 2010).

\section{Yağların GC-MS ile Analizi}

Tohum materyali $(5 \mathrm{~g})$ üç tekerrürlü olmak üzere Soxhlet ${ }^{\circledR}$ cihazında petrol eteri ile ekstrakte edilmiştir. Elde edilen sabit yağların metil esterleri
Metcalfe ve ark. (1966)'na göre hazırlanmış ve GC-MS kullanılarak bileşimlerinde bulunan yağ asitlerinin tayini yapılmıştır.

GC-MS analizleri Hewlett Packard GC 5890 II series sistemi ${ }^{\circledR}$ ile gerçekleştirilmiştir. Kullanılan kapiler kolon HP 88 (column $(100 \mathrm{~m}$ $x 250 \mu \mathrm{m} \times 0.20 \mu \mathrm{m}$ film thickness) SE-54 fused silika kapiler kolondur. Taşıyıcı gaz olarak helyum kullanılmış olup akış hızı $1 \mathrm{ml} / \mathrm{dk}$ ' dır. Elektron enerjisi $70 \mathrm{eV}$ 'tur. Enjeksiyon miktarı $1 \mu \mathrm{l}$ ' dir. Numunelerin analizi $170{ }^{\circ} \mathrm{C}$ de $1 \mathrm{dk}$, $220^{\circ} \mathrm{C}$ de $10^{\circ} \mathrm{C} / \mathrm{dk}$ ve $230^{\circ} \mathrm{C}$ de $15 \mathrm{dk}$ sicaklık programına göre gerçekleştirilmiştir. Enjeksiyonlar split modda (1:20) $250^{\circ} \mathrm{C}$ ısıda gerçekleştirilmiştir. Yağ asidi yüzdeleri üç enjeksiyonun ortalaması sonucunda elde edilmiştir.

\section{Bulgular ve Tartışma}

I. tinctoria ve I. buschiana bitkilerinden elde edilen tohumların çimlenme özellikleri üzerine vejetasyon süresinin ve sıcaklığın etkisi

Tohumların uygulanan sıcaklıklara tepkileri farklı olduğundan sıcaklık $x$ tür ve ekim zamanı $x$ tür intereksiyonları önemli $(p<0.01)$ bulunmuştur (Çizelge 1). I. buschiana tohumlarının (\%67.5), I. tinctoria'ya (\%83.2) nazaran çimlenme gücünün daha düşük olduğu ve I. tinctoria tohumlarının çimlenme oranları bakımından ekim zamanları arasında bir fark olmadığı görülmüştür. Ancak $I$. buschiana tohumlarının çimlenme oranları bakımından ekim zamanları arasında bir fark oluşmuştur. En yüksek çimlenme oranları Kasım ve Şubat aylarında ekilen bitkilerin tohumlarından elde edilmiş dolayısıyla bu iki ayda ekilen bitki tohumlarının çimlenme güçlerinin diğer aylarda ekilenlere oranla daha

Çizelge 1. Farklı sıcaklıkların Isatis tohumlarının çimlenme değerleri üzerine etkisi (\%)

Table 1. Effect of different temperatures on germination values of I. tinctoria seeds (\%)

\begin{tabular}{|c|c|c|c|c|c|c|c|c|c|c|c|}
\hline & \multicolumn{7}{|c|}{ I. buschiana } & \multicolumn{3}{|c|}{ I. tinctoria } \\
\hline & & Ekim & Kasım & Şubat & Mart & $\begin{array}{c}\text { Sıcaklık x } \\
\text { Tür Ort. }\end{array}$ & Ekim & Kasım & Şubat & Mart & $\begin{array}{c}\text { Sıcaklık x } \\
\text { Tür Ort. }\end{array}$ \\
\hline \multirow{5}{*}{$\begin{array}{l}\frac{\text { I }}{\bar{x}} \\
\frac{\mathbb{\delta}}{\omega}\end{array}$} & 5 & 16.3 & 14.2 & 14.9 & 14.5 & $15.0^{\mathrm{e}}$ & 17.9 & 19.1 & 18.5 & 18.1 & $18.3^{\mathrm{e}}$ \\
\hline & 10 & 50.0 & 48.3 & 70.0 & 51.7 & $55.0^{d}$ & 96.7 & 98.3 & 100.0 & 100.0 & $98.8^{\mathrm{a}}$ \\
\hline & 15 & 56.7 & 100.0 & 93.3 & 73.3 & $80.8^{\mathrm{C}}$ & 100.0 & 100.0 & 100.0 & 100.0 & $100.0^{\mathrm{a}}$ \\
\hline & 20 & 80.0 & 100.0 & 93.3 & 85.0 & $89.6^{\mathrm{bc}}$ & 98.3 & 100.0 & 100.0 & 100.0 & $99.6^{\mathrm{a}}$ \\
\hline & 25 & 96.7 & 100.0 & 96.7 & 96.7 & $97.5^{\mathrm{a}}$ & 100.0 & 100.0 & 96.7 & 100.0 & $99.2^{\mathrm{a}}$ \\
\hline \multicolumn{2}{|c|}{$\begin{array}{c}\text { Ekim } \\
\text { Zamanı x } \\
\text { Tür Ort. }\end{array}$} & $60.0^{\mathrm{d}_{*}}$ & $72.5^{\mathrm{bc}}$ & $73.6^{\mathrm{b}}$ & $64.2^{\mathrm{cd}}$ & 67.5 & $82.6^{a}$ & $83.5^{\mathrm{a}}$ & $83.0^{\mathrm{a}}$ & $83.6^{a}$ & 83.2 \\
\hline
\end{tabular}

*Duncan testine göre 0.01 önem düzeyine göre farklı ortalamalar farklı harflerle gösterilmiştir.

* Different averages are shown with different letters by Duncan's test at 0.01 level. 
Çömlekcioğlu et al. "Effects of Temperature, Hormone and Vegetation Period on the Germination of Isatis tinctoria L. and Isatis buschiana Schischkin Seeds and Relationship between Seed Maturity and Oil Quality"

iyi olacağı düşünülmektedir. Sıcaklık $x$ tür interaksiyonları bakımından, I. tinctoria'da çimlenme oranları $5^{\circ} \mathrm{C}$ sıcaklıkta belirgin düzeyde düşük çıkmış fakat diğer sıcaklık uygulamaları arasında bir fark olmamış ve yüksek çıkmıştır. I. buschiana'da ise, sıcaklıklar arasındaki fark önemli olup $(P<0.01)$, sıcaklık arttıkça çimlenme oranı da artmıştır. Her iki tür için ortak ekim tarihinin Subat olabileceği ve tohumların $20-25^{\circ} \mathrm{C}$ 'de en yüksek, $5^{\circ} \mathrm{C}$ 'de ise en düşük çimlenme oranlarına sahip olduğundan, sıcaklığın artmasıyla çimlenme gücünün arttığı, azalmasıyla ise düştüğü sonucu çıkarılmaktadır (Çizelge 1).

Farklı ekim zamanlarında ekilerek yetiştirilen I. tinctoria bitkisinin tohumlarıyla yapılan sıcaklık denemesinde; tüm ekim zamanlarından elde edilen tohumlarda ve tüm sıcaklık uygulamalarında yaklaşık olarak \%95'in üzerinde çimlenme oranlarına ulaşılmış; sıcaklık artışıyla çimlenme için gereken zamanın kısaldığı görülmüştür. Yalnızca $5^{\circ} \mathrm{C}$ 'lik sıcaklık uygulamasında çimlenmenin diğer sıcaklıklara göre daha geç başladığı (7. Gün), yavaş devam ettiği ve 15. güne kadar devam edip, bu tarihten sonra sabit kaldığı, ayrıca daha önce de belirtildiği gibi çimlenme oranının daha düşük olduğu görülmüştür (Şekil 2).
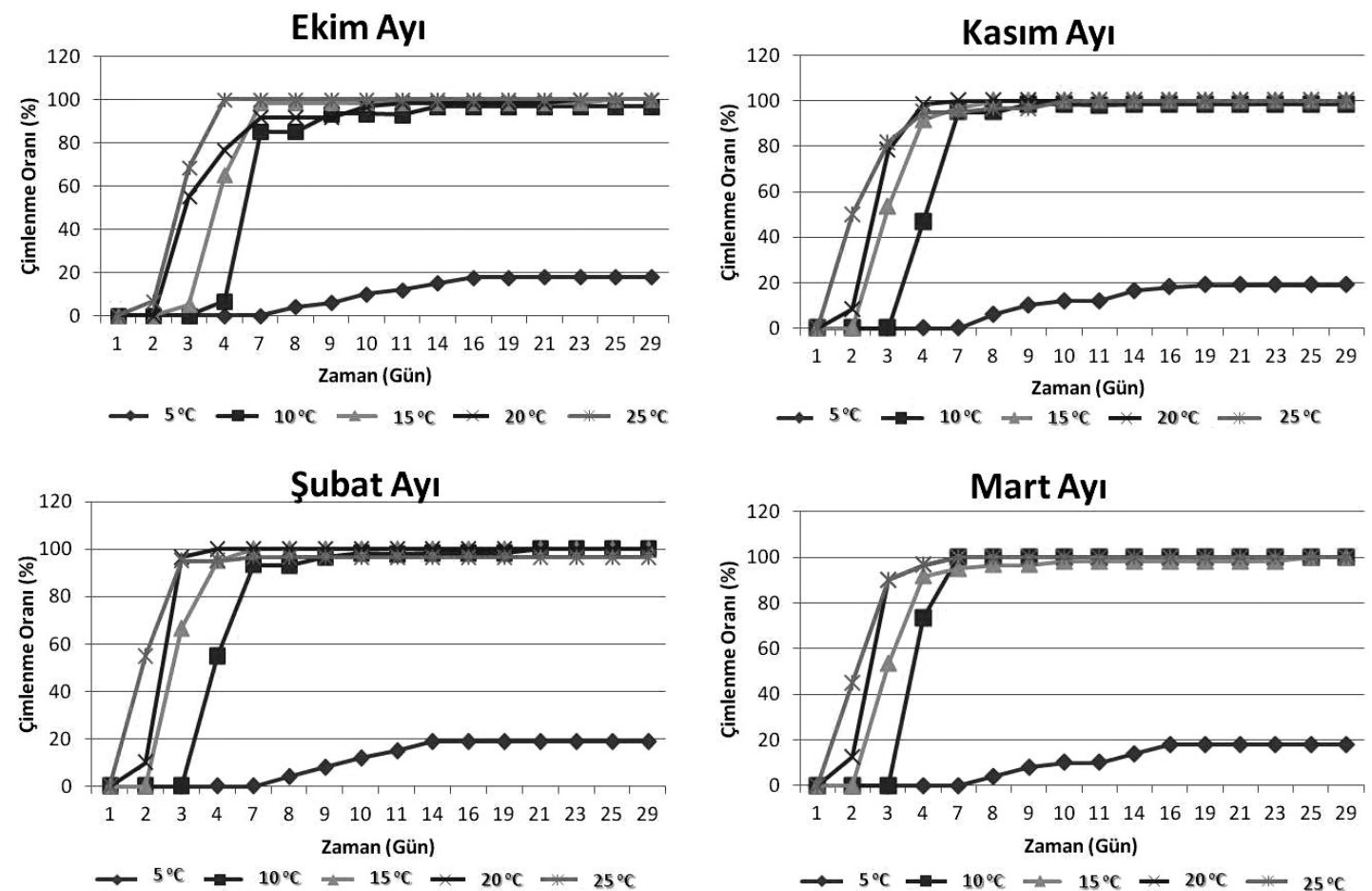

Şekil 2. Sıcaklığın I. tinctoria tohumlarının çimlenmesi üzerine etkisinin zamana bağlı değişimi Figure 2. Time dependent change of temperature effect on the germination of I. tinctoria seeds 

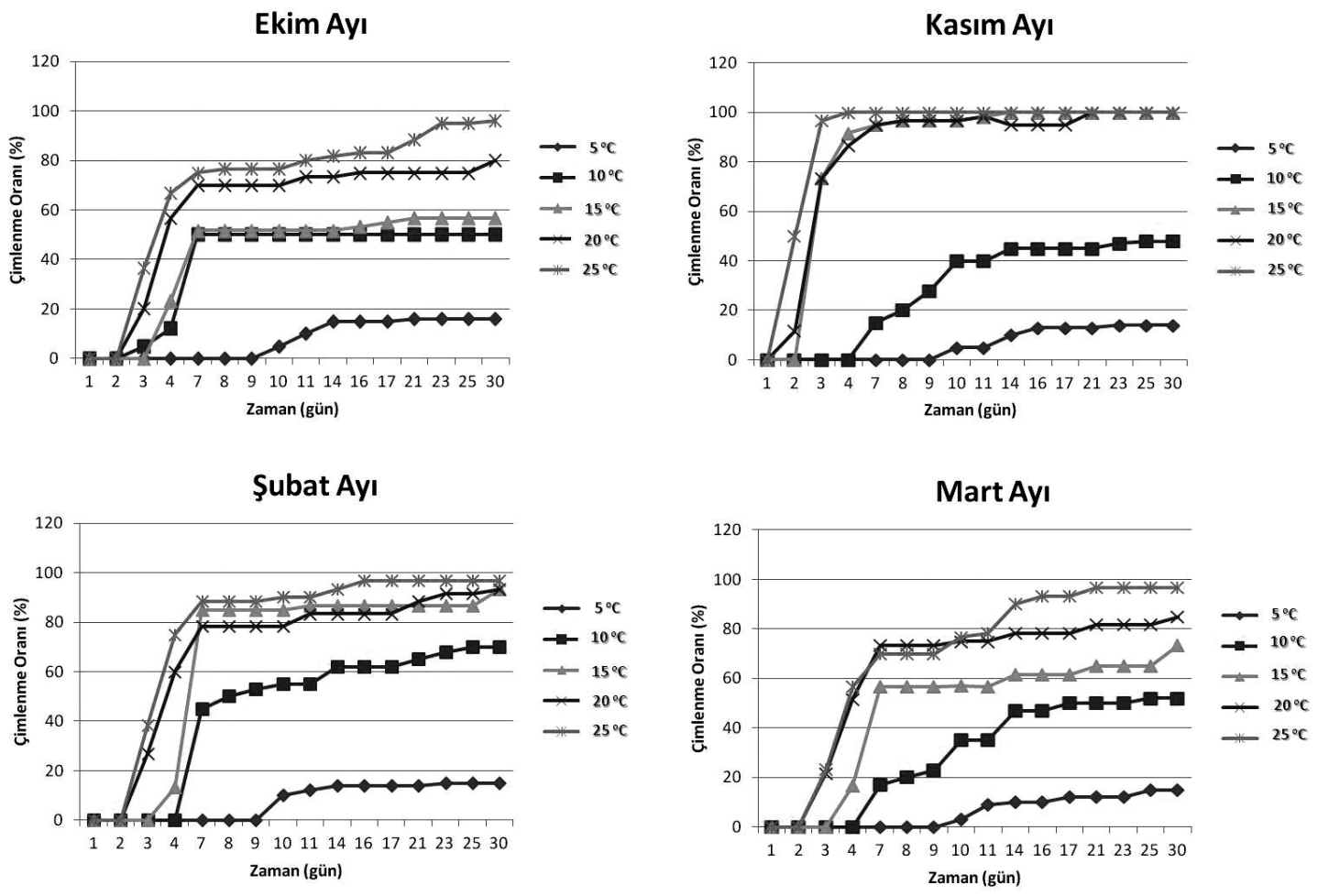

Şekil 3. Sıcaklığın I. buschiana tohumlarının çimlenmesi üzerine etkisinin zamana bağlı değişimi Figure 3. Time dependent change of temperature effect on the germination of I. tinctoria seeds

yapılacak ekimler düşük toprak sıcaklığı nedeniyle tohumların çimlenme gücünü negatif olarak etkilemektedir. Fakat birim alandan elde edilen bitki verimiyle orantılı olarak yaprak veriminin dolayısıyla yapraktan elde edilen indigo veriminin de artması yine birim alanda çıkış yapan ve hayatta kalan bitki sayısıyla ilişkilidir.

İyi bir çimlenme ve çıkış, bitkisel verimliliğin en önemli aşamalarından birini oluşturmaktadır (Turgut ve Balcı 2002). Çimlenme döneminde yaşanan abiyotik stresler çimlenmeyi olumsuz etkilemekte, çimlenme süresini uzatmakta veya çimlenmeyi engellemektedir (Korkmaz 2008; Korkmaz ve ark. 2010). Uzun sürede düzensiz olarak çimlenen bitki tohumları, ekildikleri ortamda homojen olmayan bir çıkış sergiledikleri için verimin azalmasına neden olmaktadırlar. Geç ve düzensiz çimlenme, birim alandan elde edilecek verimin azalmasının yanı sıra yabancı ot, hastalık ve zararlılar ile rekabet gücünü azaltıcı etki de yapmaktadır. Bu durum, verimi olduğu kadar kaliteyi de olumsuz etkilemektedir. Tohum ekimi ve fide çıkışı arasındaki dönemde karşılaşılan problemleri ortadan kaldırmak, ekim ile çıkış arasındaki süreyi kısaltmak, fide çıkışını üniform olarak sağlamak, çimlenme ve çıkış sorunlarını minimuma indirgemek bu nedenle önem taşır (Kaya ve ark. 2010). Bu nedenle çalışmanın ikinci aşaması olarak, bazı hormonların çeşitli konsantrasyonları ile priming yapılarak tohumların çimlenme hızı ve oranlarının en düşük olduğu $5^{\circ} \mathrm{C}$ sıcaklıkta çimlenme gücünü arttırmak hedeflenmiştir.

Tohumların düşük sıcaklıkta çimlenme özellikleri üzerine farklı hormonların etkisi

Her iki Isatis türünün $5^{\circ} \mathrm{C}$ 'lik çimlenme sıcaklığında 3 farklı hormonun farklı konsantrasyonlarına tepkileri konsantrasyon $\mathrm{x}$ tür ve hormon $\mathrm{x}$ tür ikili interaksiyonları \%1 düzeyinde bulunmuş yani türlerin hormon ve konsantrasyon uygulamalarına tepkileri farklı olmuştur. $\mathrm{GA}_{3}$ 'ün diğer iki hormona nazaran her iki türde de düşük sıcaklıkta çimlenme üzerine daha olumlu etki yaptığı ve çimlenmeyi arttırdığı sonucuna varılmıştır. Konsantrasyon x tür interaksiyonunda, I. tinctoria'da 75 ppm'lik, I. bushiana'da ise 50 ppm'lik konsantrasyonların çimlenme üzerine daha etkili olduğu görülmüştür (Çizelge 2). 
Çömlekcioğlu et al. "Effects of Temperature, Hormone and Vegetation Period on the Germination of Isatis tinctoria L. and Isatis buschiana Schischkin Seeds and Relationship between Seed Maturity and Oil Quality"

Çizelge 2. Üşüme stresi uygulanan tohumların çimlenmesi üzerine farklı hormon uygulamaları (\%) Table 2. Different hormone applications on germination of Isatis seeds subjected to chilling stress (\%)

\begin{tabular}{|c|c|c|c|c|c|c|c|c|c|}
\hline & & \multicolumn{4}{|c|}{ I. buschiana } & \multicolumn{4}{|c|}{ I. tinctoria } \\
\hline & & $\mathrm{GA}_{3}$ & ALA & Putresin & $\begin{array}{c}\text { Konsant. } \\
\text { x Tür }\end{array}$ & $\mathrm{GA}_{3}$ & ALA & Putresin & $\begin{array}{c}\text { Konsant } \\
\text { x Tür }\end{array}$ \\
\hline \multirow{4}{*}{ 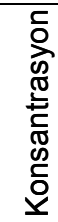 } & 0 & 16.3 & 12.7 & 14.5 & $14.5^{\mathrm{b}}$ & 19.6 & 19.4 & 15.7 & $18.2^{\mathrm{ab}}$ \\
\hline & 25 & 35.0 & 11.7 & 10.0 & $18.9^{\mathrm{ab}}$ & 25.0 & 15.0 & 8.3 & $16.1^{b}$ \\
\hline & 50 & 50.0 & 13.3 & 13.3 & $25.6^{\mathrm{ab}}$ & 38.3 & 16.7 & 20.0 & $25.0^{\mathrm{ab}}$ \\
\hline & 75 & 26.7 & 11.7 & 6.7 & $15.0^{b}$ & 49.3 & 20.0 & 31.7 & $31.7^{\mathrm{a}}$ \\
\hline \multicolumn{2}{|c|}{ Hormon x Tür } & $37.2^{\mathrm{a}}$ & $12.2^{b}$ & $10.0^{b}$ & 18.5 & $37.5^{\mathrm{a}}$ & $17.2^{\mathrm{b}}$ & $20.0^{b}$ & 22.8 \\
\hline \multicolumn{2}{|c|}{ Tür Ort. } & \multicolumn{4}{|c|}{19.8} & \multicolumn{4}{|c|}{22.0} \\
\hline
\end{tabular}

${ }^{*},{ }^{* *}$; Aynı harf grubuna giren ortalamalar arasında Duncan testine göre $\% 5$ ve $\% 1$ seviyesinde önemli farklılıklar yoktur

*,**; There is no significant difference between the groups with the same letters at $\% 5$ and $\% 1$ level,respectively.

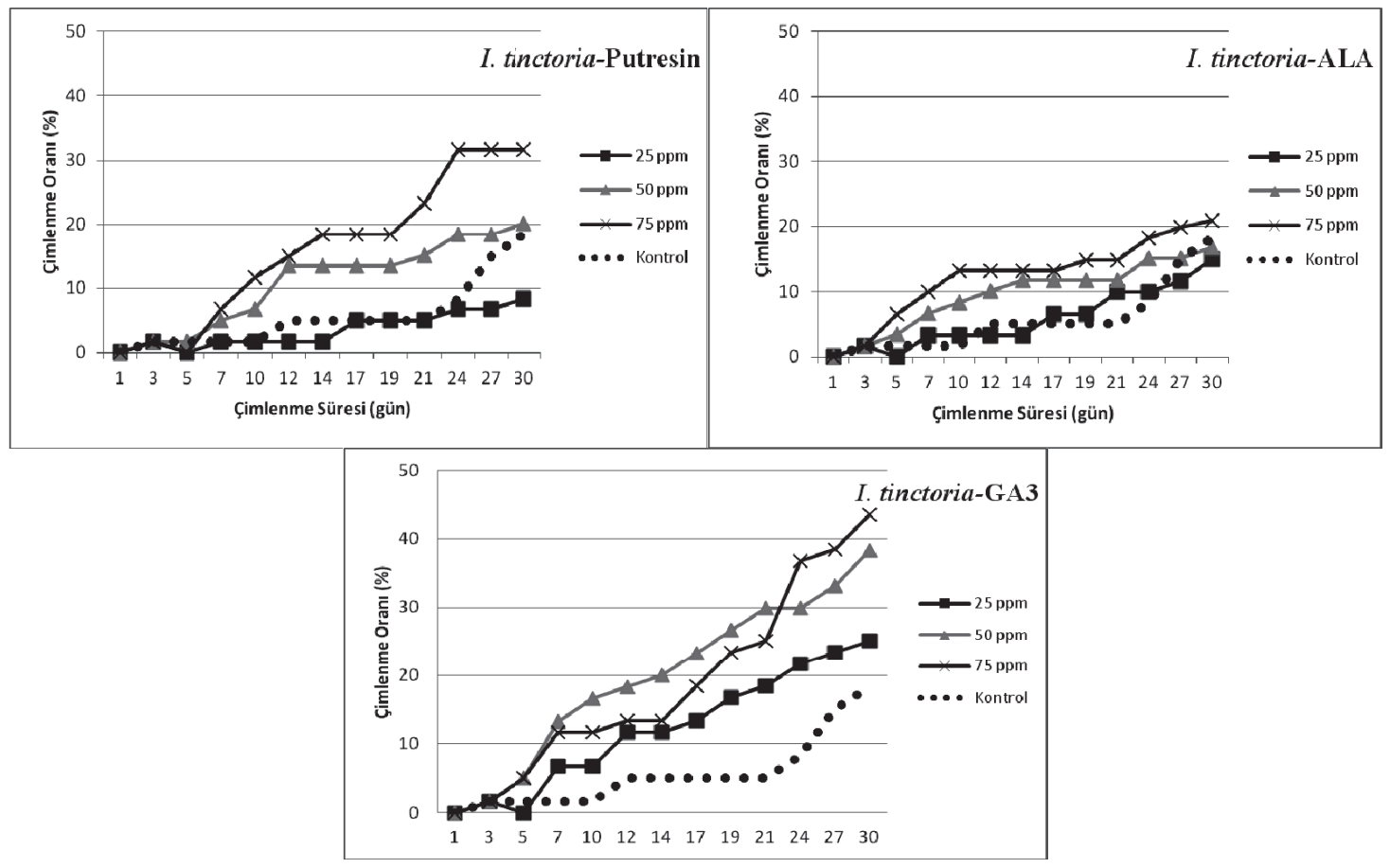

Şekil 4. Hormonların I. tinctoria tohumlarının çimlenmesi üzerine etkisinin zamana bağlı değişimi

Figure 4. Time dependent change of hormone effects on the germination of I. tinctoria seeds

Tohumların düşük sıcaklıkta çimlenmesi üzerine her iki türde de, $\mathrm{GA}_{3}$ hormonu daha etkili olurken diğer iki hormon kontrol grubuyla benzer sonuçlar vermiştir. Çimlenme oranı kontrol grubunda 21. günden sonra artış göstermiş, fakat hormon uygulamalarının hepsinde 3 . günden sonra artış olmuş ve bu durum denemenin sonuna kadar devam etmiştir (Şekil 4). I. tinctoria bitkisine uygulanan $\mathrm{GA}_{3}$ hormonunun tüm uygulamalarında deneme devam ettiği sürece çimlenmenin de devam ettiği ve kontrole göre çimlenmeyi arttırdığı ayrıca çimlenmeyi hızlandırdığı görülmektedir. ALA ve Putresin hormonlarının her ikisinde de 75 ppm'lik dozun kontrole nazaran çimlenmeyi az da olsa arttırdığı ve hızlandırdığı fakat diğer tüm konsantrasyonlarda çimlenme oranının önce arttığı sonra durduğu, daha sonra ortalama 20. günden sonra tekrar arttığı gözlenmiş̧ir (Şekil 4).

I. bushiana'da ise $\mathrm{GA}_{3}$ 'in tüm dozları kontrole göre çimlenme oranını arttırmış, 50 ppm'lik konsantrasyonda en yüksek çimlenme oranına ulaşılmış ve ortalama olarak 10. günden sonra tüm konsantrasyonlarda çimlenme oranı belirgin bir şekilde artmıştır. Putresin uygulamasında ise çimlenme oranı artmadığı gibi kontrole nazaran daha düşük değerler elde edilmiştir. $\mathrm{GA}_{3}$ hormonunun I. bushiana tohumlarının çimlenmesi üzerine bir diğer olumlu etkisi ise çimlenmeyi hızlandırması olmuştur. Tüm uygulamalarda 5. günde 
Çömlekcioğlu ve ark. "Sıcaklık, Hormon ve Vejetasyon Süresinin Isatis tinctoria L. ve Isatis buschiana Schischkin tohumlarının Çimlenmesi Üzerine Etkisi ve Tohum Olgunluğunun Yağ Kalitesi ile İlişkisi

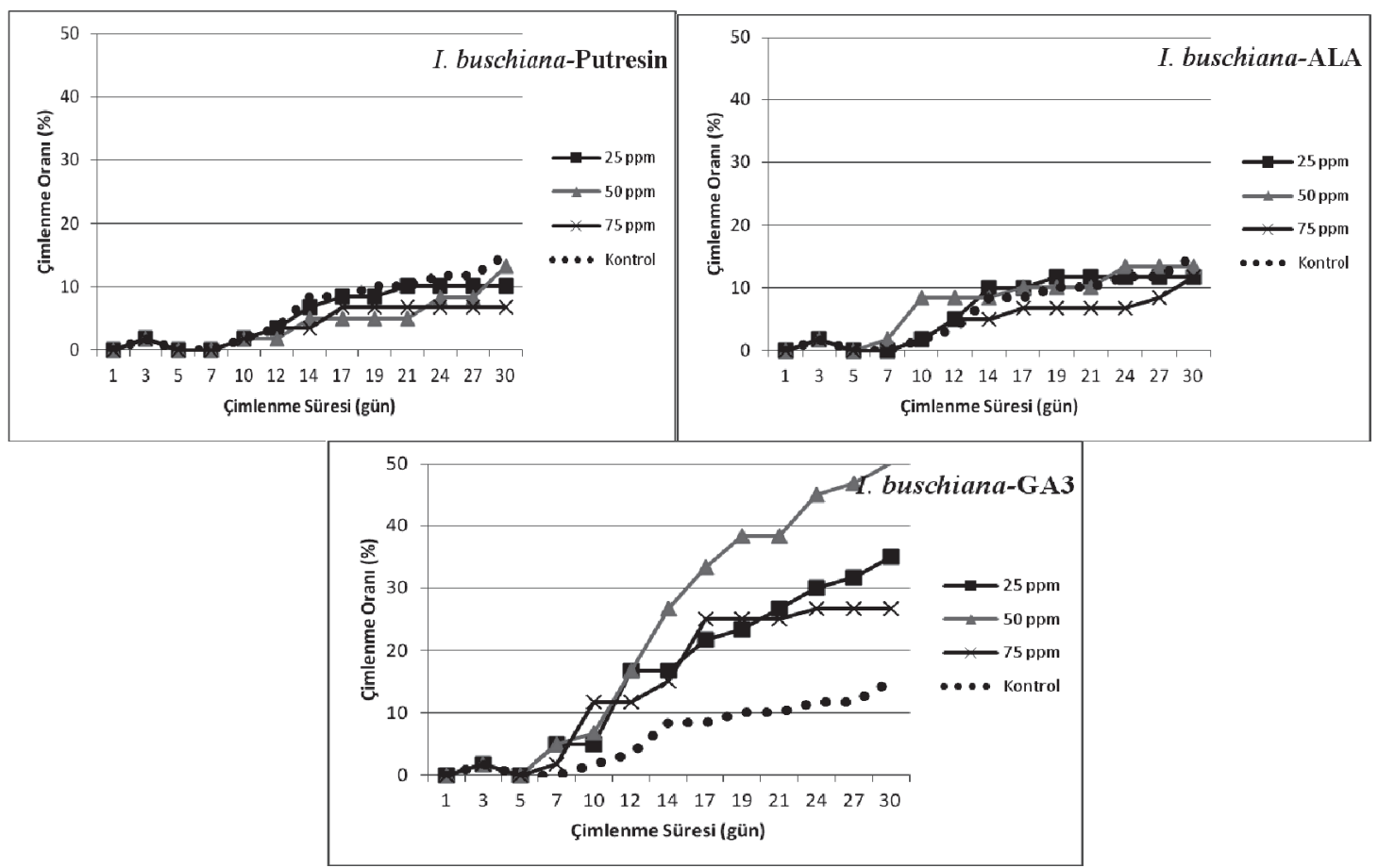

Şekil 5. Hormonların I. buschiana tohumlarının çimlenmesi üzerine etkisinin zamana bağlı değişimi

Figure 5. Time dependent change of hormone effects on the germination of I. buschiana seeds

çimlenme başlarken, kontrol uygulamasında 10. I. buschiana'da daha yüksek bulunmuştur günü bulmuştur. ALA uygulamasının sadece 50 ppm'lik konsantrasyonunda benzer bir etki görülmüş, çimlenme diğer konsantrasyonlara nazaran daha erken başlamıştır (Şekil 5). ALA'nın stres koşulları altında tohum çimlenmesi üzerine etkisi hakkında literatürdeki bilgi sınırlı olup, düşük ve yüksek sıcaklıklar bitki içerisindeki ALA biyosentezini olumsuz etkilemektedir (Korkmaz 2008). Bu çalışmada ALA'nın çimlenme gücü üzerine etkisiz kaldığı fakat çimlenme hızını az da olsa arttırdığı görülmüştür.

Duman (2007), uygulama görmüş tohumların hızlı ve yüksek oranda çimlenme ve çıkış gösterdiklerini, bu tohumlardan sağlanan erken, hızlı ve homojen çimlenme ve fide çıkışının homojen bitki gelişimi ile birim alan verim üzerine de olumlu etki yaptığını belirtmiştir. Bazı araştırmacılar priming uygulamasının toplam çimlenme yüzdesinden ziyade çimlenmenin hızı üzerine daha etkili olduğu sonucuna varmıştır (Atalay ve ark. 2011). Bu çalışmadaki sonuçların literatür bilgilerini destekler nitelikte olduğu ifade edilebilir.

Isatis spp. Tohumlarından Elde Edilen Yağın Analizi (Çizelge 3). I. buschiana ve I. tinctoria'da sabit yağ asidi ana bileşenlerini linolenik, erusik, oleik ve linoleik asitlerin oluşturduğu görülmektedir (Çizelge 4). Ayrıca her iki türde de \%1'in üstünde olan yağ asitleri palmitik, nervonik, stearik ve araşidik asitlerdir. Diğer yağ asitleri \% 1'in altında kalmıştır. Ekim zamanları arasında belirgin bir fark bulunmamıştır. Yağ asitleri çeşitlilik bakımından oldukça zengin olmasına karşılık, miktar bakımından 4 ana yağ asidi (linolenik, erusik, oleik, linoleik) diğerlerine oranla daha fazla bulunmaktadır. I. tinctoria bitkisinin tohumlarındaki yağın \%8.03'ü, I. buschiana'nın ise \%7.51'i doymuş yağ asitleri olup, yağın geri kalan kısmını ise doymamış yağ asitleri oluşturmaktadır.

Çizelge 3. I. buschiana ve I. tinctoria tohumlarına ait yağ verimleri $(\%)$

Table 3. Oil yields (\%) of I. tinctoria and I. buschiana seeds

\begin{tabular}{lcc}
\hline Ekim zamanları & I. buschiana & I. tinctoria \\
\hline Ekim & $33.91 \pm 0.417$ & $27.94 \pm 0.176$ \\
Kasım & $34.01 \pm 0.089$ & $29.66 \pm 0.262$ \\
Şubat & $31.11 \pm 1.479$ & $27.43 \pm 0.243$ \\
Mart & $31.90 \pm 0.190$ & $30.15 \pm 0.046$
\end{tabular}


Çömlekcioğlu et al. "Effects of Temperature, Hormone and Vegetation Period on the Germination of Isatis tinctoria L. and Isatis buschiana Schischkin Seeds and Relationship between Seed Maturity and Oil Quality"

Çizelge 4. I. buschiana ve I. tinctoria tohum yağlarının GC/MS analizi

Table 4. GC/MS analysis of I. tinctoria and I. buschiana seed oils

\begin{tabular}{|c|c|c|c|c|c|c|c|c|}
\hline & \multicolumn{5}{|c|}{ I. buschiana } & \multicolumn{2}{|c|}{ I. tinctoria } & \\
\hline & \multicolumn{8}{|c|}{ Ekim Zamanları } \\
\hline & Ekim & Kasım & Şubat & Mart & Ekim & Kasım & Şubat & Mart \\
\hline Miristik Asit & $0.07^{\star}$ & $0.08 \pm 0.01$ & $0.09 \pm 0.01$ & $0.08 \pm 0.01$ & $0.06 \pm 0.01$ & $0.09 \pm 0.01$ & $0.08 \pm 0.01$ & $0.08 \pm 0.01$ \\
\hline Pentadekanoik Asit & 0.04 & $0.05 \pm 0.01$ & 0.05 & 0.04 & $0.06 \pm 0.02$ & $0.05 \pm 0.01$ & $0.06 \pm 0.01$ & $0.06 \pm 0.01$ \\
\hline Palmitik Asit & $4.01 \pm 0.02$ & $4.18 \pm 0.07$ & $3.97 \pm 0.06$ & $4.13 \pm 0.02$ & $3.71 \pm 0.11$ & $4.11 \pm 0.05$ & $4.32 \pm 0.01$ & $3.62 \pm 0.02$ \\
\hline Palmitoleik Asit & $0.25 \pm 0.02$ & $0.32 \pm 0.01$ & 0.21 & $0.27 \pm 0.01$ & $0.08 \pm 0.01$ & $0.27 \pm 0.01$ & $0.37 \pm 0.01$ & $0.33 \pm 0.01$ \\
\hline Heptadekanoik asit & 0.09 & $0.09 \pm 0.01$ & 0.07 & 0.09 & $0.05 \pm 0.01$ & - & $0.06 \pm 0.01$ & $0.06 \pm 0.01$ \\
\hline cis-10 Heptadekanoik & 0.11 & $0.10 \pm 0.01$ & - & 0.12 & - & - & - & - \\
\hline Stearik Asit & $1.10 \pm 0.01$ & $1.17 \pm 0.02$ & 0.97 & $1.13 \pm 0.01$ & $1.11 \pm 0.04$ & $1.26 \pm 0.01$ & $1.33 \pm 0.01$ & 1.07 \\
\hline Oleik Asit & $18.59 \pm 0.09$ & $17.83 \pm 0.27$ & $16.39 \pm 0.18$ & $18.83 \pm 0.05$ & $16.39 \pm 0.21$ & $17.48 \pm 0.26$ & $19.96 \pm 0.1$ & $16.22 \pm 0.23$ \\
\hline Linoleik Asit & $9.31 \pm 0.03$ & $9.38 \pm 0.09$ & $10.78 \pm 0.08$ & $9.63 \pm 0.03$ & $12.13 \pm 0.12$ & $12.23 \pm 0.15$ & $11.98 \pm 0.03$ & $12.06 \pm 0.13$ \\
\hline Araşidik Asit & $1.02 \pm 0.01$ & $1.18 \pm 0.045$ & $0.95 \pm 0.01$ & $0.95 \pm 0.01$ & $1.05 \pm 0.01$ & $1.08 \pm 0.02$ & $1.19 \pm 0.01$ & $1.01 \pm 0.01$ \\
\hline Eikosatrienoik asit & - & - & $0.19 \pm 0.01$ & $0.20 \pm 0.01$ & - & $0.24 \pm 0.01$ & $0.21 \pm 0.01$ & $0.19 \pm 0.01$ \\
\hline Linolenik asit & $34.56 \pm 0.01$ & $33.46 \pm 0.05$ & $33.23 \pm 0.27$ & $34.95 \pm 0.29$ & $31.24 \pm 0.05$ & $31.75 \pm 0.53$ & $31.07 \pm 0.31$ & $29.72 \pm 0.51$ \\
\hline Eikosadienoik asit & $0.77 \pm 0.01$ & $0.89 \pm 0.12$ & $0.85 \pm 0.01$ & $0.81 \pm 0.01$ & $0.97 \pm 0.01$ & $0.92 \pm 0.04$ & $0.82 \pm 0.025$ & $0.88 \pm 0.02$ \\
\hline Behenik asit & $0.51 \pm 0.01$ & $0.68 \pm 0.09$ & $0.54 \pm 0.02$ & $0.47 \pm 0.01$ & $0.82 \pm 0.01$ & $0.79 \pm 0.07$ & $0.83 \pm 0.05$ & $1.09 \pm 0.28$ \\
\hline Erusik Asit & $24.18 \pm 0.07$ & $24.21 \pm 0.15$ & $25.58 \pm 0.04$ & $23.03 \pm 0.01$ & $25.73 \pm 0.13$ & $23.63 \pm 0.16$ & $22.94 \pm 0.04$ & $26.5 \pm 0.46$ \\
\hline Dokosandienoik asit & $0.44 \pm 0.01$ & $0.52 \pm 0.06$ & $0.54 \pm 0.04$ & $0.45 \pm 0.01$ & $0.68 \pm 0.01$ & $0.58 \pm 0.03$ & $0.46 \pm 0.04$ & 0.54 \\
\hline Lignoserik Asit & $0.39 \pm 0.03$ & $0.54 \pm 0.07$ & $0.46 \pm 0.01$ & $0.35 \pm 0.02$ & $0.64 \pm 0.05$ & $0.56 \pm 0.03$ & $0.57 \pm 0.07$ & $0.47 \pm 0.02$ \\
\hline Nervonik Asit & $2.91 \pm 0.01$ & $3.04 \pm 0.03$ & $3.17 \pm 0.07$ & $2.73 \pm 0.01$ & $2.48 \pm 0.04$ & $2.43 \pm 0.08$ & $2.07 \pm 0.09$ & $2.51 \pm 0.09$ \\
\hline Kalendik Asit & - & - & - & $0.35 \pm 0.01$ & - & $0.23 \pm 0.01$ & 0.41 & - \\
\hline Toplam & 98.33 & 97.68 & 98.01 & 98.56 & 97.17 & 97.65 & 98.69 & 96.37 \\
\hline
\end{tabular}

* 0.01 'in altında olan standart hatalar çizelgede gösterilmemiştir.

* Standard error values under 0.01 has not been shown.

I. cappadocica subsp. steveniana, I. kotschyana, I. candolleana, I. spectabilis, I. kozlowskyi ve I. glauca subsp. glauca türlerine ait bitki yağlarında linolenik (\%26.2-32.6 arasında), erusik (\%14.2-23.6), oleik (\%13.218.8) ve linoleik (\%8.94-15.86) asitler major bileşenler olarak bildirilmiş ayrıca eikosenoik asitin varığıda tespit edilmiştir (Bağcı ve Özçelik 2009). Kızıl ve ark. (2009), I. aucherii, I. cochlearis, I. constricta, I. demiriziana,

l.

glauca ve I. lusitanica'nın başlıca yağ asitlerini erusik (\%14.69-30.52), oleik (\%14.16-24.91), linoleik (\%2.74-12.78), linolenik asit (\%11.7929.08) olduğunu, ayrıca palmitik asidin de (\%5.45-20.39) önemli miktarda bulunduğunu göstermişlerdir. Ayrıca bu türlerde laurik asit, azelaik, tetradekanoik, palmitoleik, hekzadekanoik, tetrakosenoik asitleri de tanımlanmıştır (Kızıl ve ark. 2009). I. tinctoria'da ise başlıca yağ asitleri sırasıyla linolenik (\%27.4 ve 28.5 ), oleik (\%17.7 ve 23.8), linoleik (\%15.212.6) olarak belirtilmiştir (Blatger 1993).

Bitkilerde bulunan mevcut etkili madde miktarlarını etkileyen çeşitli faktörler bulunmaktadır. Yağ oranı ve kimyasal bileşenlerin türlere, bitki kısımlarına, gelişme dönemlerine, ekolojik faktörlere ve genetik yapıya göre değişebileceği bildirilmektedir (Ceylan 1994). Mastebroek ve ark. (1994), tohum eldesi ve yağ miktarının çevresel koşullardan oldukça etkilenirken, tohumlardaki yağ asitleri ve glukosinolat miktarının etkilenmediğini bildirmişlerdir. Benzer şekilde aynı familyaya mensup önemli bir endüstri bitkisi olan Crambe abyssinica üzerinde yapılan çeşitli araştırmalarda erusik asit içeriğinin oldukça stabil olduğu ve çevreden etkilenmediği anlaşılmıştır (Bondioli ve ark. 1998; Fontana ve ark. 1998). Yağ asidi profilinin ekolojik şartlarla ilgili olmadığı bildirilmiştir (Yaniv ve ark. 1991).

\section{Sonuç}

Bitkilerin yaşamı çimlenmeyle başlar ve bunu fidelerin hayatta kalma başarısı takip eder. İyi bir çimlenme ve çıkışın verim ve üretimin en önemli aşamalarından birini oluşturması prensibinden hareketle (Erdoğan 2008), bir bitkinin öncelikle çimlenme özellikleri bilinmelidir. Fakat verim ve üretim çevresel stres faktörleriyle sınırlandırılmakta, sürdürülebilir tarım ise stres faktörlerini tolere edebilen türlere intiyaç duymaktadır. Bu çalışmada Isatis cinsine ait iki bitkinin (I. tinctoria ve $l$. buschiana) tohumlarının çimlenme fizyolojisi ve yağlarının içeriği araştırılmıştır. 
Çömlekcioğlu ve ark. "Sıcaklık, Hormon ve Vejetasyon Süresinin Isatis tinctoria L. ve Isatis buschiana Schischkin tohumlarının Çimlenmesi Üzerine Etkisi ve Tohum Olgunluğunun Yağ Kalitesi ile İlişkisi

I. tinctoria tohumlarının çimlenmesi üzerine vejetasyon süresinin etkili olmadığı; fakat I. bushiana için bu durumun önem arzettiği, Şubat ve Kasım ekimlerinde ekilerek yetiştirilen bitkilere ait tohumların çimlenme oranlarının da arttığı görülmektedir. Her iki türde de $5^{\circ} \mathrm{C}$ 'de en düşük olmak üzere, düşük sıcaklıkta çimlenmesinin yavaş olduğu, sıcaklık arttıkça çimlenmenin de hızlandığı; I. bushiana'nın $I$. tinctoria'ya nazaran daha yavaş ve düşük oranda çimlendiği gözlenmiştir. Düşük sıcaklıkta çimlenme toleransını arttırmak için uygulanan farklı konsantrasyonlardaki hormonlarla yapılan deneme sonuçları $\mathrm{GA}_{3}$ 'in diğer iki hormona göre (Putresin ve ALA) daha etkili olduğunu ve kontrol uygulamasına kıyasla çimlenmeyi belirgin bir şekilde arttırdığını göstermiştir. Konsantrasyon bakımından ise 50 ve 75 ppm'lik konsantrasyonun en etkili doz olduğu belirlenmiştir. I. tinctoria ve I. buschiana'nın aynı cins ve familya içerisindeki diğer bitkilerle aralarında yağ verimi ve yağ asidi içeriği bakımından bazı farklar vardır. Bu farkların bitkilerin genetik yapısından kaynaklandığı, hasat zamanı ve ekolojik şartların yağ asidi içeriğini değiştirmediği anlaşılmıştır.

\section{Teşekkür}

$\mathrm{Bu}$ çalışma Kahramanmaraş Sütçü İmam Üniversitesi tarafından desteklenmiştir (Proje No: 2013/1-29LAP).

\section{Kaynaklar}

Akıncı İ. E. ve Çalışkan Ü., 2010. Kurşunun Bazı Yazlık Sebzelerde Tohum Çimlenmesi ve Tolerans Düzeyleri Üzerine Etkisi. Ekoloji, 19(74): 164-172

Al-Gendy A. A., El-Gindi O. D., Hafez A. S., and Ateya A. M., 2010. Glucosinolates, volatile constituents and biological activities of Erysimum corinthium Boiss. (Brassicaceae). Food Chemistry, 118(3): 519-524

Atalay E., Sade B. ve Soylu S., 2011. Farklı Priming Uygulamalarının Ekmeklik Buğday'da (Triticum aestivum L.) Çimlenme ve Çıkışa Etkileri ile Fide Dönemi Su Stresine Fizyolojik Tepkilerin Belirlenmesi. TÜBITAK Proje Sonuç Raporu. Proje No: TOVAG-1100490, sf: 113 (Erişim Tarihi: 26.12.2013)

Azimova S.S., Glushenkova A.I. and Vinogradova V.I., 2011. Lipids, lipophilic components and essential oils from plant sources (Vol. 1). Springer Science \& Business Media. p:983, London

Bağcı E. ve Özçelik H., 2009. Fatty acid and tocochromanol patterns of some Isatis L. (Brassicaceae) species from Turkey. Pakistan Journal Botany, 41(2): 639-646
Blatger S., 1993. Rev. Fr. Corps Gras., 40: 241. In: K. Aitzetmuller, B Matthaus and $\mathrm{H}$. Friedrich. 2003. A new database for seed oil fatty acidsThe Database SOFA. Eur. J. Lipid Sci. Tech., 105: 92-103.

Bondioli P., Folegatti L., Lazzeri L. and Palmieri S., 1998. Native Crambe abyssinica oil and its derivatives as renewable lubricants: an approach to improve its quality by chemical and biotechnological processes. Industrial Crops and products, $7: 231-238$

Ceylan A., 1994. Tıbbi Bitkiler I. Ege Üniversitesi Ziraat Fakültesi Yayınları, 312 s. 136, İzmir

Çömlekcioğlu N., 2011. Kahramanmaraş'ta yayılış gösteren bazı Isatis spp. (Çivitotu) türlerinde farklı ekim zamanlarının verim unsurlarına etkisi ile boyama özelliklerinin ve boyarmadde miktarının saptanması. Doktora Tezi, KSÜ. Fen Bilimleri Enstitüsü (Basılmamış), Kahramanmaraş

Çömlekcioğlu N., Efe L. and Karaman S., 2015. Extraction of Indigo from Some Isatis species and Dyeing Standardization Using Lowtechnology Methods. Brazilian Archives of Biology and Technology, 58(1): 96-102

Dhanda S.S., Sethi G.S. and Behl R.K., 2004. Indices of drought tolerance in wheat genotypes at early stages of plant growth. J. Agron.ve Crop Sci, 190: 6-12

Duman İ., Eser, B., ve Tozan, M. 2007. Soğan tohumlarında ozmotik koşullandırma amacı ile kullanılan havalandırılmiş kolon tekniğinin ticari boyutlarda geliştirilmesi. Ege Üniv. Zir. Fak. Der, 44(1): 1-14

Elkoca E., 2007. Priming: Ekim Öncesi Tohum Uygulamaları. Atatürk Üniversitesi Ziraat Fakültesi Dergisi, 38 (1): 113-120.

Erdoğan G., 2008. Değişik Kimyasal Uygulamalarının Farklı İskenderiye Üçüll (Trifolium alexandrinum L.) Çeşidi Tohumlarının Düşük Sıcaklıktaki Çimlenme ve Çıkış Performansları Üzerine Etkileri. Yüksek lisans Tezi, KSÜ, Fen Bilimleri Enstitüsü (Basılmamış), Kahramanmaraş

Fontana F., Lazzeri L., Malaguti L. and Galletti S., 1998. Agronomic characterization of some Crambe abyssinica genotypes in a locality of the Po Valley, European Journal of Agronomy, 9: $117-126$

Galletti S., Barillari J., lori R. and Venturi G., 2006. Glucobrassicin enhancement in woad (Isatis tinctoria) leaves by chemical and physical treatments. Journal of the Science of Food and Agriculture, 86:1833-1838

Gilbert K.G. and Cooke D.T., 2001. Dyes from plants: Past usage, present understanding and potential. Plant Growth Regulation, 34: 57-69 
Çömlekcioğlu et al. "Effects of Temperature, Hormone and Vegetation Period on the Germination of Isatis tinctoria L. and Isatis buschiana Schischkin Seeds and Relationship between Seed Maturity and Oil Quality"

Iqbal M. and Ashraf M., 2005. Changes in Growth, Photosyntetic and Ionic Relations in Spring Wheat (Triticum aestivum L.) Due to Presowing Seed Treatment with Polyamines. Plant Growth Regulation, 46:19-30

Anonim, 1996. International rules for seed testing. Seed Science Technology, 24: 335

Karagüzel O. ve Taşçıŏlu S.G., 2005. Isatis tinctoria L.'da çimlenme özellikleri üzerine tohum yaşı ve sıcaklığın etkisi. Türküye II. Tohumculuk Kongresi, 9-11 Kasım 2005, Adana s. 265270

Karaman S., Diraz E., Çömlekçioğlu N., İlçim A., Durdu H. and Tansi S., 2015. High yielding indigo sources in native /satis (Brassicaceae) taxa from Turkey. Genetic Resources and Crop Evolution, 1-13

Kaya G., 2008. Tohum Uygulamaları (Priming)'nın Tohum Yağ Asitleri Kompozisyonuna Etkisi ve Tohum Kalitesi ile İlişkisi. Tarla Bitkileri Merkez Araştırma Enstitüsü Dergisi, 17(1-2)

Kaya G., Demir I., Tekin A., Yaşar F. and Demir K., 2010. Priming Uygulamasının Biber Tohumlarının Stres Sıcaklıklarında Çimlenme, Yağ Asitleri, Şeker Kapsamı ve Enzim Aktivitesi Üzerine Etkisi. Tarım Bilimleri Dergisi, 16: 9-16

Kenanoğlu B.B., Demir I., Mavi K., Yetişir H. and Keleş D., 2007. Effect of priming on germination of Lagenaria siceraria genotypes at low temperatures. Tarım Bilimleri Dergisi, 13(3): 169-175

Kızıl S., Murat T., Cakmak O., Özgüven M. and Khawar K.M., 2009. Microelement Contents and Fatty Acid Compositions of some Isatis Species Seeds. Notulae Botanicae Horti Agrobotanici Cluj-Napoca, 37(1): 175-178

Korkmaz A., Tiryaki I., Nas M.N. and Özbay N., 2004. Inclusion of Plant Growth Regulators into Priming Solution Improves Low Temperature Germination and Emergence of Watermelon Seeds. Canadian Journal of Plant Science, 84:1161-1165

Korkmaz A., 2005. Inclusion of acetyl salicylic acid and methyl jasmonate into the priming solution improves low temperature germination and emergence of sweet pepper seeds. Hort Science, 40: 197-200

Korkmaz A., 2008. Biberde Çimlenme ve Fide Gelişimi Sırasında Üşüme Stresine Karşı Toleransın 5-Aminolevulinik Asit (ALA) Uygulamaları İle Arttırılması. Tübitak Proje Sonuç Raporu, Proje No: 1070611, pp: 48 (Erişim Tarihi: 21.06.2012)
Korkmaz A., Korkmaz Y. and Demirkıran A.R., 2010 Enhancing chilling stress tolerance of pepper seedlings by exogenous application of 5aminolevulinic acid. Environmental and Experimental Botany, 67(3): 495-501

Lin L.Z. and Harnly J.M., 2010. Phenolic component profiles of mustard greens, yu choy, and 15 other Brassica vegetables. Journal of agricultural and food chemistry, 58(11): 68506857

Mastebroek H.D., Wallenburg S.C. and Soest L.J.M., 1994. Variation for agronomic characteristics in Crambe (Crambe abyssinica Hochst. Ex Fries), Industrial Crops and products, 2:129-136

Hegarty, T. W. 1971. A relation between field emergence and laboratory germination in carrots. J. Hort. Sci. 46: 299-305.

Metcalfe L.D., Schmitz A.A. and Pelka J.R., 1966. Rapid preparation of fatty acid esters from lipids for gas chromatographic analysis. Analytical Chemistry, 38(3): 514-515

Moazzeni H., Zarrea S., Al-Shehbaz İ.A. and Mummenhoff K., 2007. Seed-coat microsculpturing and its systematic application in Isatis (Brassicaceae) and allied genera in İran. Flora, 202:447-454

Mungan A., 2005. Kahramanmaraş Ekolojik Koşullarında Farklı Ekim Zamanları ve Ekim Sıklıklarının Lesqurella fendleri' nin Verim ve Kalitesine Etkisi. Doktora tezi, Çukurova Üniversitesi, Fen Bilimleri Enstitüsü (Basılmamış), Adana

Murungu F.S., Chiduza C., Nyamugafata P., Clark L.J., Whalley W.R. and Finch-Savage W.E., 2004. Effects of 'On-farm Seed Priming' on Consecutive Daily Sowing Occasions on the Emergence and Growth of Maize in Semi-Arid Zimbabwe. Field Crops Research, 89:49-57.

Öztürk Ö., 2000. Bazı Kışlık Kolza Çeşitlerinde Farklı Ekim Zamanı ve Sıra Arası Uygulamalarının Verim, Verim Unsurları ve Kalite Üzerine Etkileri. Doktora Tezi, Selçuk Üniversitesi, Fen Bilimleri Enstitüsü, (Basılmamış), Konya.

Turgut İ. ve Balcı A., 2001. Bursa koşullarında değişik ekim zamanlarının şeker mısırı (Zea mays saccharata Sturt.) siceraria çeşitlerinin taze koçan verimi ile verim öğeleri üzerine etkileri. Tarla Bitkileri Kongresi, Tahıllar ve Yemeklik Tane Baklagiller (I): 195-199

Yaniv Z., Elber Y., Zur M. and Schafferman D., 1991. Differences in fatty acid composition of oils of wild cruciferae seed, Phytochemistry, 30:841-843.

Yıldız M., Kasap E. ve Konuk M., 2007. Tuzluluk, sıcaklık ve ışığın tohum çimlenmesi üzerine etkileri. Afyon Kocatepe University Journal of Science, 6(1-2):241-260 